\title{
Variability of Forage Pecking in Pigeons
}

\author{
Martina Siemann \& Juan D. Delius
}

\section{Abstract}

The pecking of birds has been classically considered a fixed action pattern that is little modified by varying internal and external circumstances. Although recent research has documented several instances of variability, the stereotypy of pecking by pigeons continues to be stressed. The present study illustrates the adaptability of the response employing an accelerometric/videographic technique. It is demonstrated that it is influenced by several experimental conditions mimicking natural contexts. The effects of admixture of non-nourishing grit, non-removability of food items, degree of deprivation, application of head loads and grain size, on the detailed course of pecking are described. A number of different, recurring types of pecking patterns were recognized but even within these the frequency, timing, extent, speed, and/or vigour of several component movements varied specifically in response to the various experimental treatments. Appreciable inter- and intraindividual variations still occur under identical conditions. In conjunction with additional evidence it is concluded that the pecking of pigeons exhibits a remarkable flexibility that conforms poorly with a fixed action pattern characterization. Accelerometry promises to be an efficient and economic aid in the analysis of the sensory, neural and motor mechanisms of avian pecking.
\end{abstract}

Corresponding author: M. SIEMANN, Allgemeine Psychologie, Universität Konstanz, W-7750 Konstanz, F. R. Germany.

\section{Introduction}

Since Charles DARwIN the variety of avian bills and feeding techniques have been popular as examples of morphological and behavioural adaptation. More recently the food-handling by birds has interested behavioural ecologists concerned with optimal foraging. Pecking has also come to the fore as a vertebrate motor pattern amenable to a physiological analysis. Involving a precise grasping of objects, its mechanisms might provide a model for robot manipulator control. Avian grasping may be simpler in this respect than primate grasping, a much studied preparation.

Pecking in birds has been traditionally viewed as a fixed action pattern (Tinbergen 1951). Thorpe (1951) defined these as "an inherited, relatively complex movement pattern within instinctive behaviour, which is as characteris- 
may vary, but its form is little, if at all, modifiable by external stimuli”. Even though later ethologists have qualified the extent of both innateness and invariance (SCHLEIDT 1974) and introduced the softer concept of modal action patterns (BARLOw 1977; see also PELIIS 1985), stereotypy continues to be stressed in connection with pigeon pecking. ZwEERS (1982a) for instance characterized it as a variable sequence of fixed action patterns and GOODALE (1983) described at least its earlier phases as highly stereotyped.

Observations of pigeons feeding in natural environments suggest, however, that their pecking behaviour is in fact quite flexible. To document some of the variability we designed four different experimental foraging situations. Exp. I compares the pecking behaviour of pigeons when simply feeding on grains and when selecting grains among grit. Exp. II examines what happens when uptake is prevented by grains glued to the substrate. Exp. III describes the influence of increasing hunger on pecking behaviour. Finally, Exp. IV investigates the effect of head loads upon pecking. As pecking is a very fast movement and high speed cinematography or videography is cumbersome and expensive, observations were implemented with accelerometry supplemented with normal video.

The account begins, however, with a brief description of pecking in pigeons based on own unsystematic observations and previous research. Apart from providing a general context, the account also introduces some of the terminology used in the later sections.

\section{Description of Pecking}

When foraging in natural situations pigeons typically go repeatedly through 3 behavioural stages: reconnoitering, nearing and pecking. During the first two phases the pigeon pauses several times to visually fixate. The early fixations are probably monocular, the later ones, mostly associated with the initiation of a peck are binocular (FRIEDMAN 1975). While fixating head and eyes remain temporarily immobile (BLOCH et al. 1988; WOHLSCHLÄGER et al., subm.). Monocular fixations probably involve lateral gazing with the fovea centralis specialized for distant viewing (BLOCH et al. 1984; HAHMANN \& GÜNTÜRKüN, in prep.). Binocular fixations, however, are accompanied by convergent eye movements (MARTINOYA et al. 1984). The relevant postero-dorsal area of the pigeon's retina is specialized for nearby binocular viewing (EMMERTON 1983; JAHNKE 1984). Usually two definite fixation stops precede a given peck (GOODALE 1983) but the way food presents itself, scattered or heaped, above or at ground level, may modify that (ZWEERS 1982a). These fixations are typically followed by approach head moves. As the beak tip moves towards the grain after the final fixation, the beak starts to open, simultaneously the eyes begin to close (DEICH et al. 1985), presumably as protection against dirt backscatter (DELIUS 1985) and the beak contacts the grain (ZEIGLER et al. 1975). In spite of some active braking the bill normally collides with the substrate (ZwEERs 1982a). The grain is grasped as the mandibles close around it (ZwEERs $1982 \mathrm{a}$; DEICH et al. 1985). Then the pigeon elevates its head while the eyes are opened again. The grain is moved through the gape with head, mandible and tongue movements. Small seeds stick to the tongue and are transported by lingual retraction (glue-and-slide); larger grains are transported with head jerks accompanied by beak opening and closures (throwand-catch; ZWEER's terms modified to make them more descriptive). Repositioning of seeds within the beak tip prior to transport involves similar mandibulation. This component may aid sensory texture and taste evaluations (grains are occasionally rejected at this stage; ZWEERS 1982 a). Swallowing, often in the course of further head lifting closes the sequence.

Although here we are concerned with the pecking shown during foraging, pigeons also produce peck-like responses in several other situations: exploration, drinking (ZWEERs 1982 b), preening (DELIUS 1988), aggression (RAMIREZ \& DELIUS 1978), courtship (FABRICIUS \& JANSSON 1963), nesting, hatching and parenting (DeliUs 1985). In addition pigeons can be taught to peck keys and other manipulanda with classical, instrumental and social conditioning paradigms (DELIUS 1983). A pharmacologically (apomorphine) induced form of pecking has also received some attention (LINDENBLATT \& Delius 1987).

\section{Experiment I: Selection of Edible Item}

In nature pigeons are frequently forced to uncover and select food morsels mixed with non-edible items. Pecks then deal both with loose substrate and actual food (HAAG 1991). Items are either just scattered or grasped and then either swallowed or dropped. A mixture of grains and grit offered in a trough mimics this situation. The task has similarities with arrangements used to investigate the discriminative abilities of chicken and pigeons (DAwKINS 1971; BOND 1983 ANDREW 1983; GÜNTÜRKÜN 1987; JÄGER 1990).

\section{Methods}

Four adult domestic pigeons (Columba livia) of local homing stock were used (birds \# 1, 2, 3 and 5). They were housed in individual cages in a ventilated room with a $12-\mathrm{h}$ dark/light cycle. Whil the birds were anesthetized, a small aluminium block $(3.5 \times 6 \times 1.5 \mathrm{~mm})$ with a $2-\mathrm{mm}$ diam. threaded perforation was cemented onto the skull just behind and between the ocular orbits (MALIIN \& DELIUS 1983). After the animals had recovered they were deprived of food until they attained $80 \%$ of their free-feeding weight.

For recording an uniaxial miniature accelerometer (Piezotronics, main axis sensitivity $0.5 \mathrm{mV}$ / $\left(\mathrm{m} / \mathrm{s}^{2}\right)$, cross sensitivity $<5 \%$, frequency response $5 \mathrm{~Hz}-25 \mathrm{kHz}$ ) mounted on a support was screwed onto the head block. The accelerometer axis pointed about $30^{\circ}$ front downward with respect to the eye centers/beak tip plane. The assembly weighed $3.7 \mathrm{~g}$ (Fig. $1 \mathrm{~A}$ ).

The pigeon was placed into a wire-mesh cage $(30 \times 30 \times 40 \mathrm{~cm})$ with a front wall of transparen plastic. The adjoining right side wall had a square $17 \times 13 \mathrm{~cm}$ opening $10 \mathrm{~cm}$ above the floor. A transparent plastic enclosure $(14 \times 9 \times 10 \mathrm{~cm})$ with an inner trough $(9 \times 5 \times 2 \mathrm{~cm})$ was hung under the opening (Fig. 1B). The trough was filled with either a mixture of 30 grains of milo (diam. about $4 \mathrm{~mm}$ ) and $30 \mathrm{~g}$ of rock grit (about 1000 pebbles; grit/grain condition) or simply with 30 grains of milo (grain only condition). The enclosure was removed $30 \mathrm{~s}$ after the first peck. 8 grit/grain presentations (grain only condition). The enclosure was removed $30 \mathrm{~s}$ after the first peck. 8 grit/grain presentations on one day served as pretraining. 8 further grit/grain and 2 grain-only presentations on the following day were recorded. The pigeons picked up

all grains in the grain-only presentation

The accelerometer output was led via an elastically suspended cable, amplified and filtered $(1-100 \mathrm{~Hz}$; Neurolog). It is convenient to refer to the signals as "celerations" since they reflect both accelerations and decelerations of forward as well as backward head movements. The celerations were 


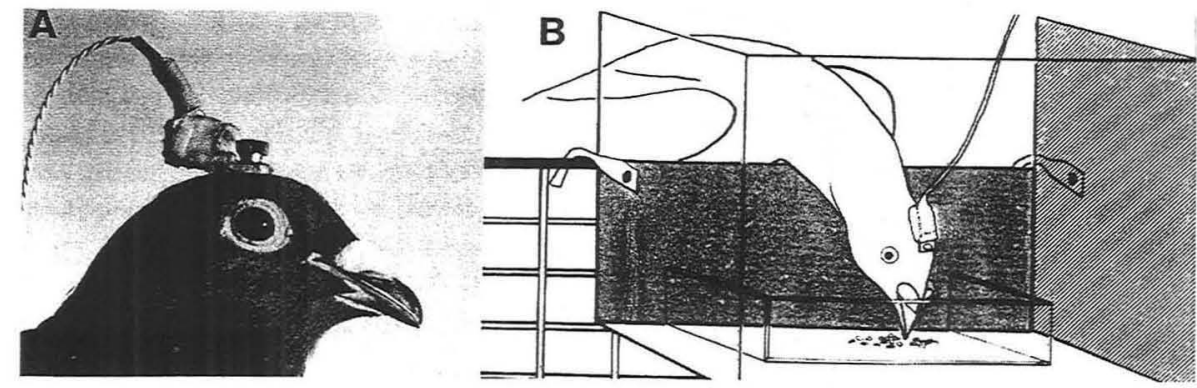

Fig. 1: Pigeon wearing miniature accelerometer (A); enclosure with inset trough (B)

stored with a tape-recorder (Teac) and displayed on a digital oscilloscope (Siemens) placed next to the cage. Head movements (mostly viewed sidewards but sometimes frontally) and oscilloscope display were jointly videographed (25 frames/s; Panasonic).

The most frequent types of pecks were identified by slow motion inspection of the video recordings. Representative exemplars of each type of peck and from each animal were selected for closer analysis. Head outlines and celeration traces were transferred from the monitor screen frame by frame onto scaled transparent paper. The corresponding celeration records were digitized with an interface (Keithley, sampling rate $1000 \mathrm{~Hz}$ ) and stored in a computer (IBM). These records were plotted and matched with the drawings. 8 of them were superimposed with the instant of substrate impact synchronized and averaged. Peak celerations associated with the various peck-phases were measured off the baseline. Means based on 8 such exemplar pecks of each type were computed for the different subjects. These subject means were the data entered in non-parametric statistical tests (BORTZ et al. 1990).

\section{Results}

The simplest kind of peck involved grasping a grain and swallowing it. It was dominant in the grain only condition. Such a peck is illustrated in Fig. $2 \mathrm{~A}$. The upper row depicts the head outlines from fixation until swallowing. During fixation the head was held still and the eyes converged (frames 1/2). A few ms after the approach was initiated the eyes began to close and the beak started to open (frame 3). As the grain was contacted the beak closed over it (frames 4/5). The head began to elevate and the eyes opened again. The grain adhered to the tongue tip and was transported back by lingual retraction through the open gape (frame 7). The sequence ends with swallowing and a renewed fixation (frames 8/9) preceding a further peck. The action lasted $360 \mathrm{~ms}$, an about average duration for a successful, uncomplicated peck (but see later).

The celeration function (Fig. 2A) starts at baseline level reflecting the head arrest during visual fixation. During the forward thrust the trace shows a biphasic course, an acceleration followed by a more gradual deceleration. Coinciding with grain/substrate contact (frame 4 ) there is a strong deceleration, downward peak. A further negative deflection signals the initiation of the upward movement. The positive deflection terminating in a steep peak indicates the ending of the head elevation with an actual brief forward head jerk. The flat section at the end corresponds to the fixation prior to the next peck.
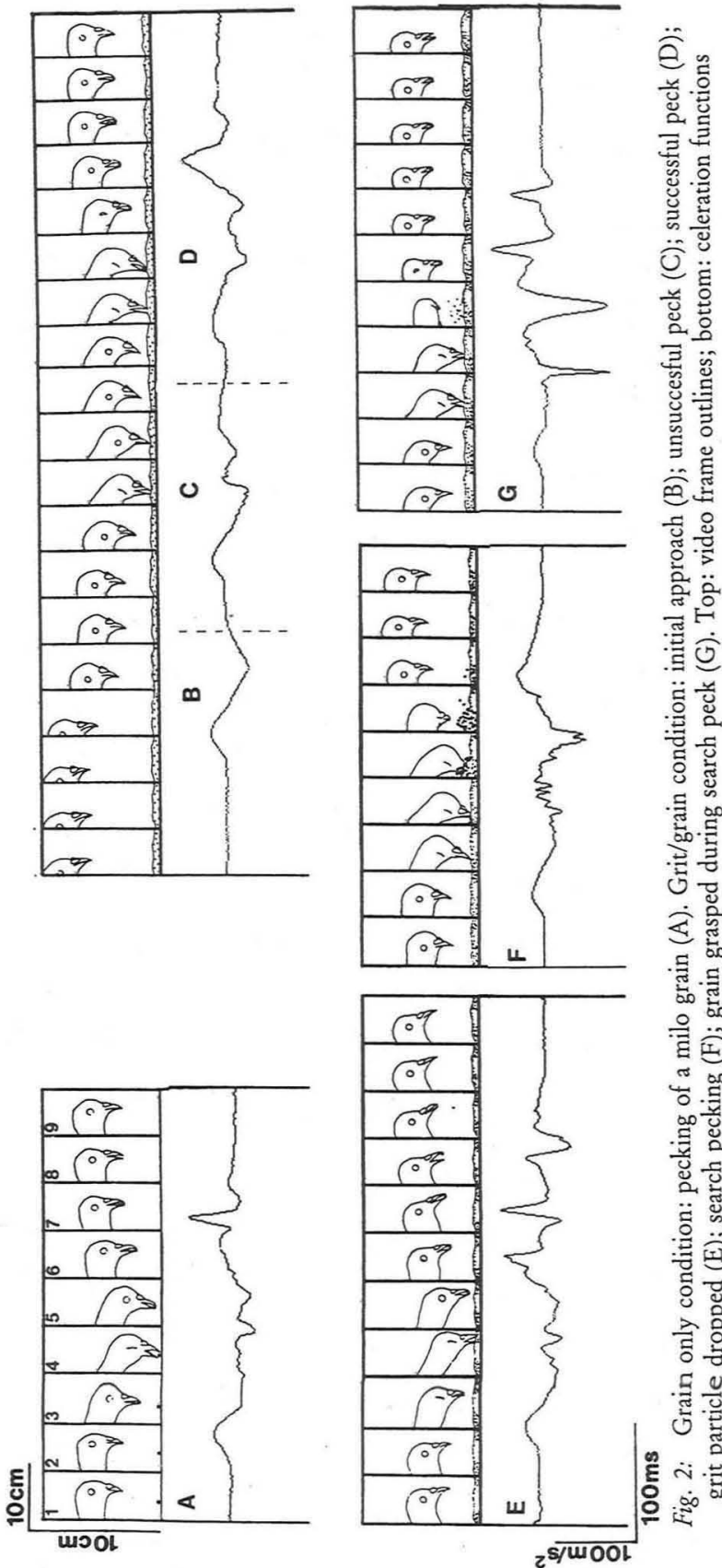
$\mathrm{p}=0.06$ ). This is likely to be due to the quasi-viscous dampening by the loose substrate. Acceleration during elevation differs between unsuccessful, successful grain uptake pecks and pecking grit (Page test for $\mathrm{D}<\mathrm{C}<\mathrm{E}$ : $\mathrm{L}=56, \mathrm{p}<0.01$ ). Grit is repositioned more often than is grain: vigorous head jerks are thus more probable.

\section{Discussion}

The video and particularly the celerations reveal much peck variability. Identifiable types of pecking recurred but, nevertheless, no two pecks by a given pigeon were ever absolutely identical. The selection of grains out of grit clearly yielded a greater variety than the simple uptake of grains. Only successful and unsuccessful pecks occurred in the grain-only condition. In the grain/grit condition there additionally was search pecking and pecking of pebbles. The latter were sometimes swallowed, but normally just dropped after repeated repositioning. Occasionally, the particle was vehemently thrown away with a head-shake. Sometimes a grain was taken up in the course of a search peck, occasionally a grain was repositioned several times in much the same way as grit before being rejected or swallowed. Individual differences were apparent both with respect to the actual movements and to the frequency with which the different kinds of pecks were produced. Two birds (\# 1 and 2) for instance very rarely showed search pecking.

The interpretation of the celeration records requires a cautionary comment. In an accelerometer a piezoelectric element converts the inertial forces of a mass attached to it into voltages that are proportional to the assembly celerations (WEISS 1947). Simple accelerometers as the one used here are unidirectional. They yield proportional positive and negative specified potentials for forward and backward celerations along their main axis. System noise is negligible but they are partially sensitive to celerations at angles of the main axis with a minimum at directions perpendicular to it (NIGG 1977). Gravity $\left(9.81 \mathrm{~m} / \mathrm{s}^{2}\right)$ registers when the main axis rotates from horizontal to vertical. Centrifugal forces become relevant when the accelerometer is moved along a circular path. These components are clearly all operative to some extent during pecking. A tri-axial accelerometer would help but they are too voluminous at present. The fact that accelerometers are not sensitive to constant celerations (no response at $0 \mathrm{~Hz}$ ) means that the records cannot be unequivocally converted by integration into velocity and position functions that are easier to interpret. The celeration data are nevertheless quite adequate for descriptive purposes.

\section{Experiment II: Prevention of Grain Uptake}

In the preceding experiment the picking up of items was essentially unobstructed. Pigeons in nature occasionally find grains frozen to the ground or corn attached to cobs. The experiment examined how the pecking is affected by an analogous laboratory situation.
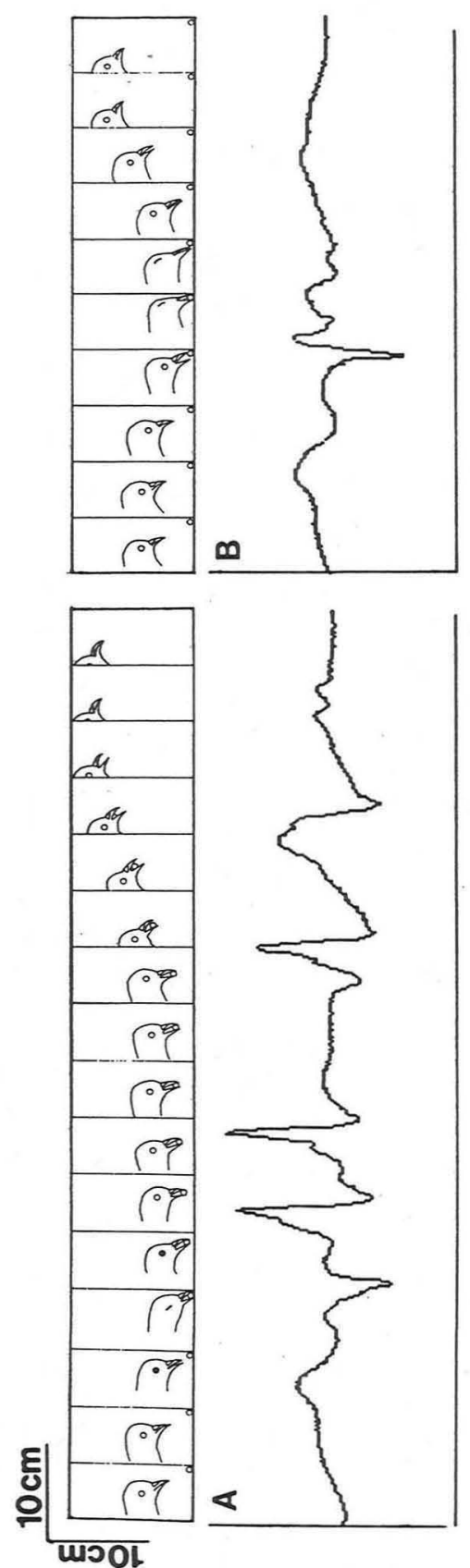
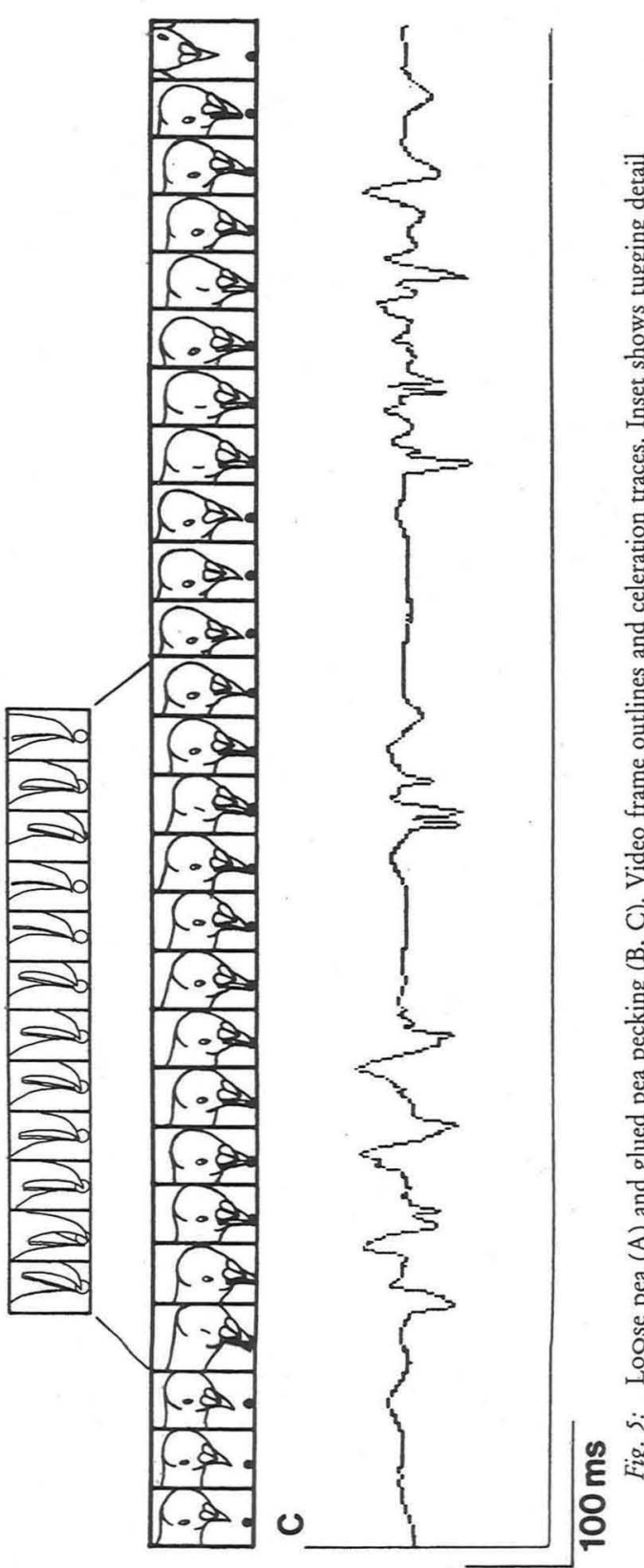

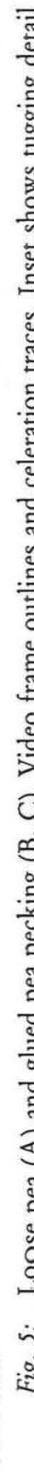

$2^{\text {s/moOl }}$ 
Methods

The same pigeons as in Exp. I were used. They were deprived to $80 \%$ of their ad libitum weight. A horizontal slotted frame $(9.5 \times 6.5 \mathrm{~cm})$ was attached to the inside of the cage side wall $6 \mathrm{~cm}$ above the floor. An opaque plastic plate $(7.5 \times 4.5 \mathrm{~cm})$ bearing two peas (diam into two depressions ( $2.5 \mathrm{~mm}$ deep, $2 \mathrm{~cm}$ apart) could be slid into this frame. invisibly glued down. Its left or right position varied according to a quasi-random sequas (GELLERMANN 1933). A session consisted of 10 presentations, each yielding at least one peck to the oose pea and serveral pecks to the glued one. Each subject participated in two succeck to the

\section{Results}

The loose peas were pecked in much the same way as the milo seeds except that the beak was opened wider (DEICH et al. 1985) and that transport was often preceded by repeated repositioning head jerks (Fig. $5 \mathrm{~A}$ ), a common response with larger seeds (ZwEERs 1982a). Repositioning movements were rarely obvious on the video pictures but they were quite apparent in the celeration traces. In most cases the pigeons repositioned the peas with up to three (two in the example shown, Fig. 5A) throw-and-catch movements while they transported them with one or two (as in the example) such movements. During repositioning the seed

A

A
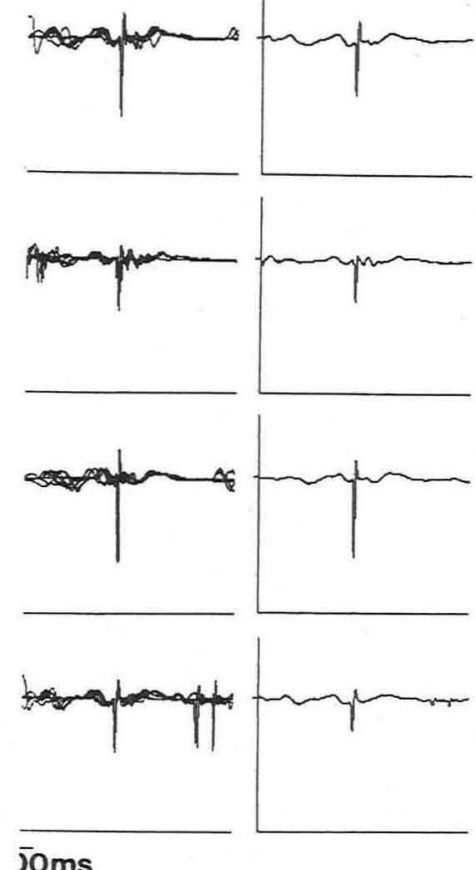

$\overline{0} \mathrm{~ms}$
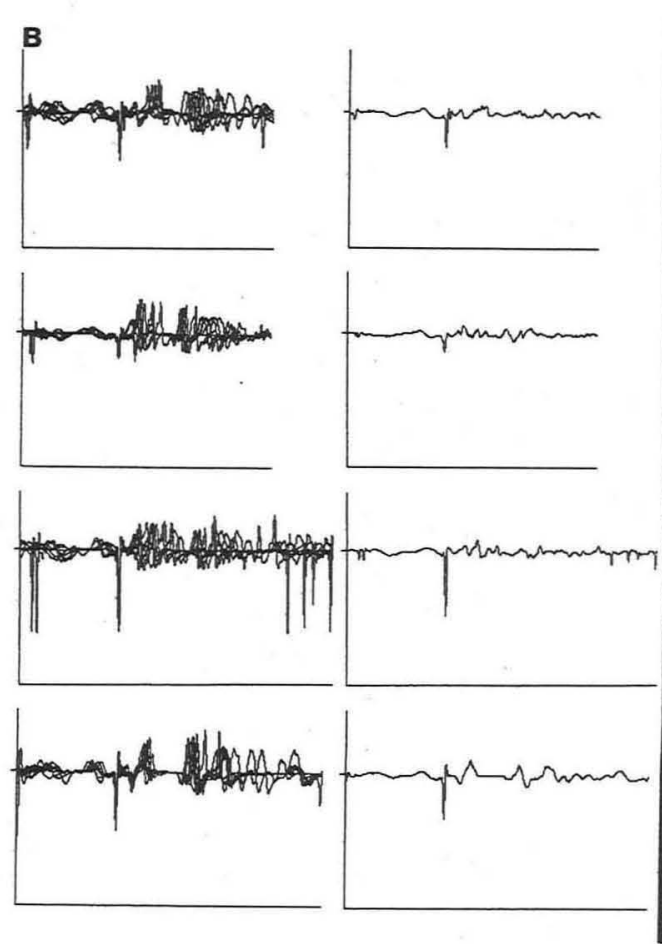

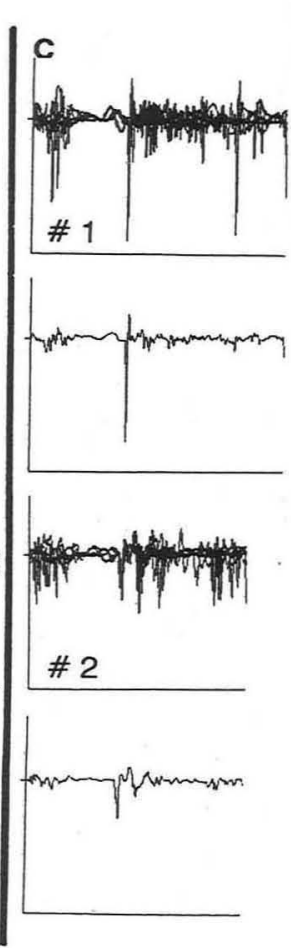

Fig. 6: Superimposed and mean celeration functions of loose pea pecks (B) and glued pea pecks: brief grasping (A), tugging $(C)$. Four $(A, B)$ and two $(C)$ pigeons was released for a few milliseconds during elevation and recaught with a short forward movement with the tip of the mandibles. For transport the seeds were recaught deeper in the gape; the extent of the forward lunge was thus less constrained.

Stuck peas were pecked in two differing ways. Mostly the beak tips were brought into brief contact with the seed, followed by immediate elevation of the head (Fig. 5B). On fewer occasions tugging occurred (Fig. 5 C), i.e. the pigeons grasped, pulled, let go, regrasped and pulled again, often repeatedly. Grasps usually lasted longer than with loose peas. While the eyes were closed during the approaches they were often intermittently opened during tugging.

Fig. 6 displays the celerations for 8 pecks per animal and peck type (A: pecks to a fixed pea, B: pecks to a loose pea, C: tugging). Celeration traces after the initial beak-grain contact in tugging show many negative peaks, due to arrested upward movements (Fig. 6C). The mean celerations synchronized at substrate impact again yield a fair description from the last approach until the start of elevation but degrade afterwards. There are again obvious inter-individual differences between pigeons, particularly regarding loose pea pecks (Fig. 6B). Birds \# 3 and 5 tugged so rarely that there were not enough records for compilation (Fig. 6C).

Fig. 7 shows celeration of repositioning and transport movements during the uptake of loose peas, synchronized with respect to their backward deceleration/ forward acceleration maxima. They reveal that both kinds of movements differ subtly in terms of head motion. Repositioning throw-and-catch movements (A) are associated with celeration peaks that are narrower and steeper than those related to transport motions (B). The celeration traces suggest some stereotypy but it must be remembered that a very standardized item was handled.

Fig. 8 depicts the mean peak celerations during the approach, contact and elevation phases of both types of pecks. While the peak approach accelerations are comparable, the collision deceleration is possibly greater when pecking glued peas. Peak backward deceleration/forward accelerations during elevation are greater for loose peas than for glued peas. The difference, however, does not quite reach significance (Wilcoxon test, $\mathrm{T}=0, \mathrm{p}=0.06$ ).

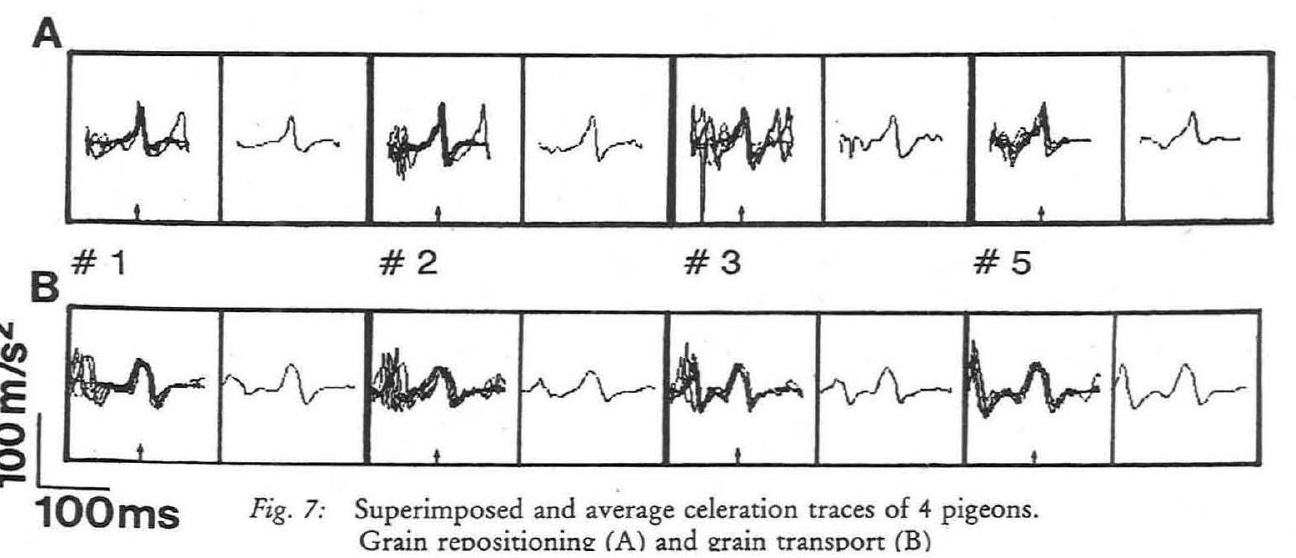




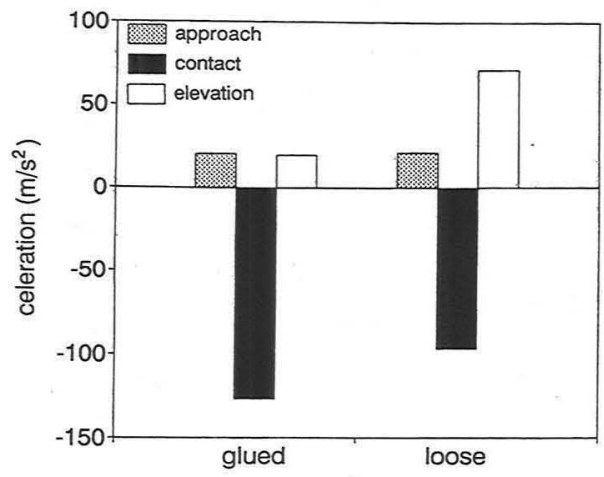

Fig. 8: Mean peak celerations during approach, contact and elevation of glued and loose pea pecks, 4 pigeons

\section{Discussion}

Peas stuck to the substrate sometimes elicited persistent tugging. Most often, however, pecks at them only involved brief, repeated attempts to grasp. The pigeons did not seem to learn that having picked-up the unfixed pea, the remaining pea was fixed. They always pecked it, only giving up eventually. With the loose peas the differences between repositioning and transport throw-andcatch actions were more distinct than with the smaller seeds used in Exp. I.

\section{Experiment III: Influence of Hunger}

ZEIGLER and collaborators have reported that the latency to initiate feeding and the interpeck intervals become shorter with increasing food deprivation (MEGIBOW \& ZEIGLER 1968; ZEIGLER et al. 1980), but they could not detect other peck modifications in their cinematographic records. The issue is reinvestigated with accelerometry.

\section{Methods}

Four adult pigeons, (\# 1, 2, 3 and 6) were used. A shock sensor (23 mm diam., $3 \mathrm{~mm}$ high) with a rim around it (10 $\mathrm{mm}$ high) mounted on a horizontal heavy metal platform, served as a trough. Its signals were amplified and recorded along with the celeration signals.

The pigeons were successively kept at $25 \%, 15 \%$ and $5 \%$ below free-feeding weight, first in the order given, then in reverse order. No food was given during the $24 \mathrm{~h}$ prior to an experimental session. Each session consisted of 3 trials. For each trial the trough was filled with about $60-70$ grains of millet (diam. about $2 \mathrm{~mm}$ ). This quantity weighed about $0.4 \mathrm{~g}$ assuring minimal satiation. A trial terminated when all grains were consumed, that is within about 20 to $70 \mathrm{~s}$ after the first peck.

Digitized peak sensor signals corresponding to beak impacts were detected with the computer. The duration of 400 intervals between such impacts (regardless of peck type) were measured for each animal and deprivation level. The celeration functions of 8 representative successful pecks for each animal were evaluated as before.

Pecking efficiency was assessed in separate trials for each subject and deprivation level. The trough used in Exp. I was filled with $10 \mathrm{~g}$ of millet (about 1600 grains). The birds were allowed access to it for 3 min beginning from the first peck. The amount consumed was determined by weighing the remaining grains. The total number of pecks per trial was derived from the video records.

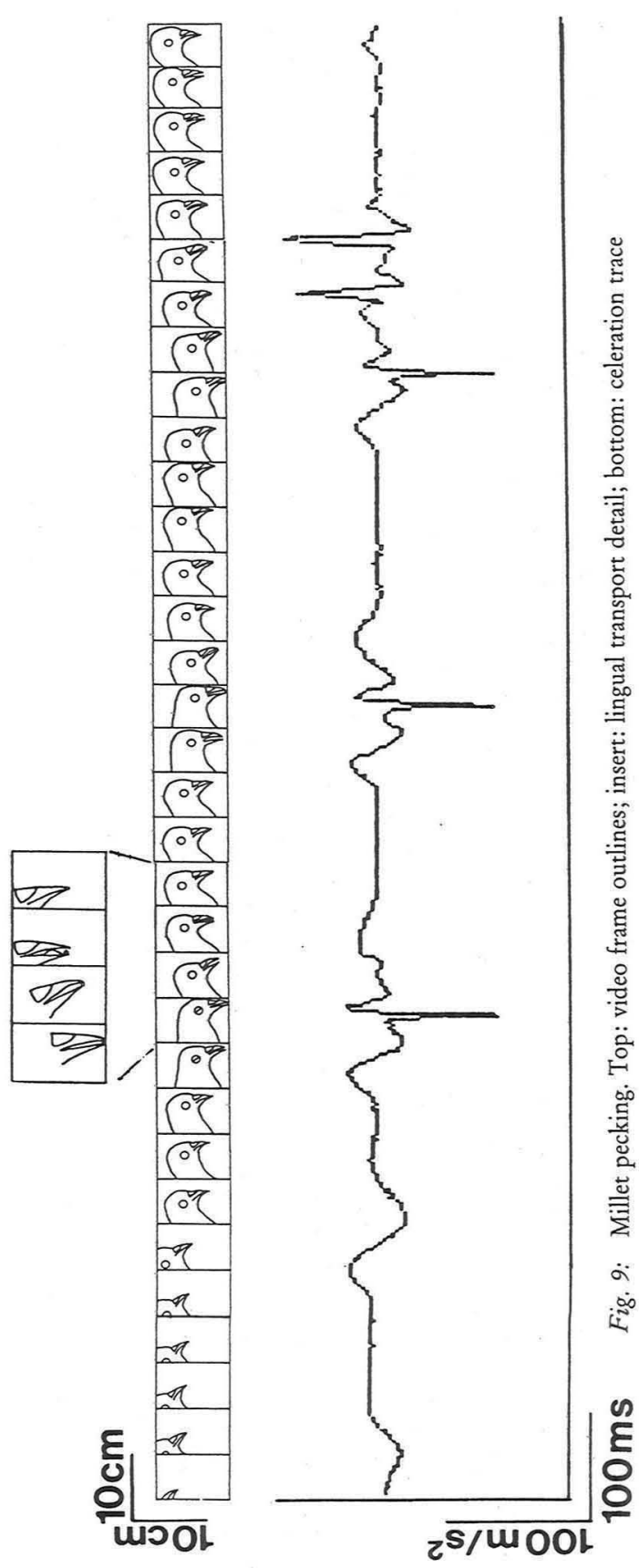




\section{Results}

When the pigeons were strongly deprived (25\% and $15 \%$ levels) they initiated feeding immediately. The $5 \%$ deprivation often yielded delayed and interrupted feeding. Fig. 9 depicts the first three pecks of a bout in the $15 \%$ condition. While approaching the pigeon fixated twice, the first fixation being longer than the second one. Between subsequent pecks the pigeon fixated only once. The third peck reveals two post-impact celeration peaks reflecting short repositioning head jerks. They were not transport movements. Millet grains are always transported with the glue-and-slide action not involving any sharp head thrusts (Fig. 9, detail).

With increasing deprivation both the median and modal inter-peck intervals became increasingly shorter (Figs. 10,11 ; Page test: $L=54 ; p=0.05$ ). The pecking efficiency, defined as the quotient between the weight of food consumed and the number of pecks issued, increased (Page test: $\mathrm{L}=54 ; \mathrm{p}=0.05$ ). When very hungry the animals managed to eat more per peck than when less hungry. This was mainly due to a less frequent dropping rather than by a better grasping of grains.

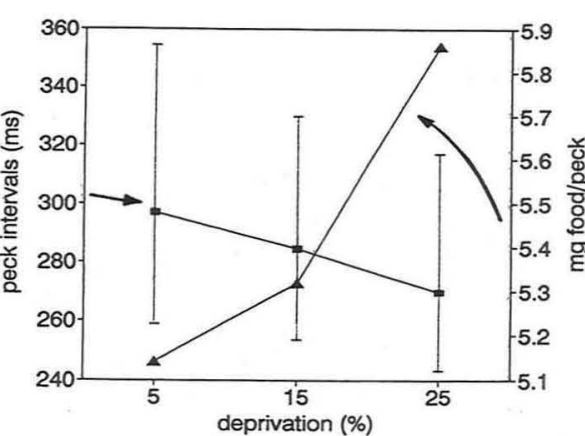

deprivation $(\%)$
Fig. 10: Mean pecking efficiency (food $[\mathrm{mg}] /$ peck) and median inter-peck intervals (vertical lines: upper and lower quartiles) as a function of food deprivation, 4 pigeons
Fig. 12 shows that during approach mean peak accelerations increase only insignificantly, mean contact decelerations increase appreciably with increasing hunger in spite of considerable inter- and intra-individual variance (Page test: $\mathrm{L}=54, \mathrm{p}=0.05$ ). Mean elevation accelerations may have decreased slightly due to the scarcity of repositioning movements.

\section{Discussion}

As reported by ZEIGLER et al. (1980) the inter-peck intervals decreased with increasing hunger. The generally shorter intervals recorded by us may be due to the very small seeds used (see later). Hungry pigeons often fixated only once before initiating the next peck, whereas rather satiated pigeons frequently interrupted feeding, reinitiating pecking with two fixations. Pecking movements themselves are affected in at least one respect. The deceleration upon substrate contact increased with deprivation, indicating a deployment of more force during the approach phase.
Fig. 11: Frequency distribution of inter-peck intervals $(n=1200)$ for the three levels of food deprivation,

$$
4 \text { pigeons }
$$
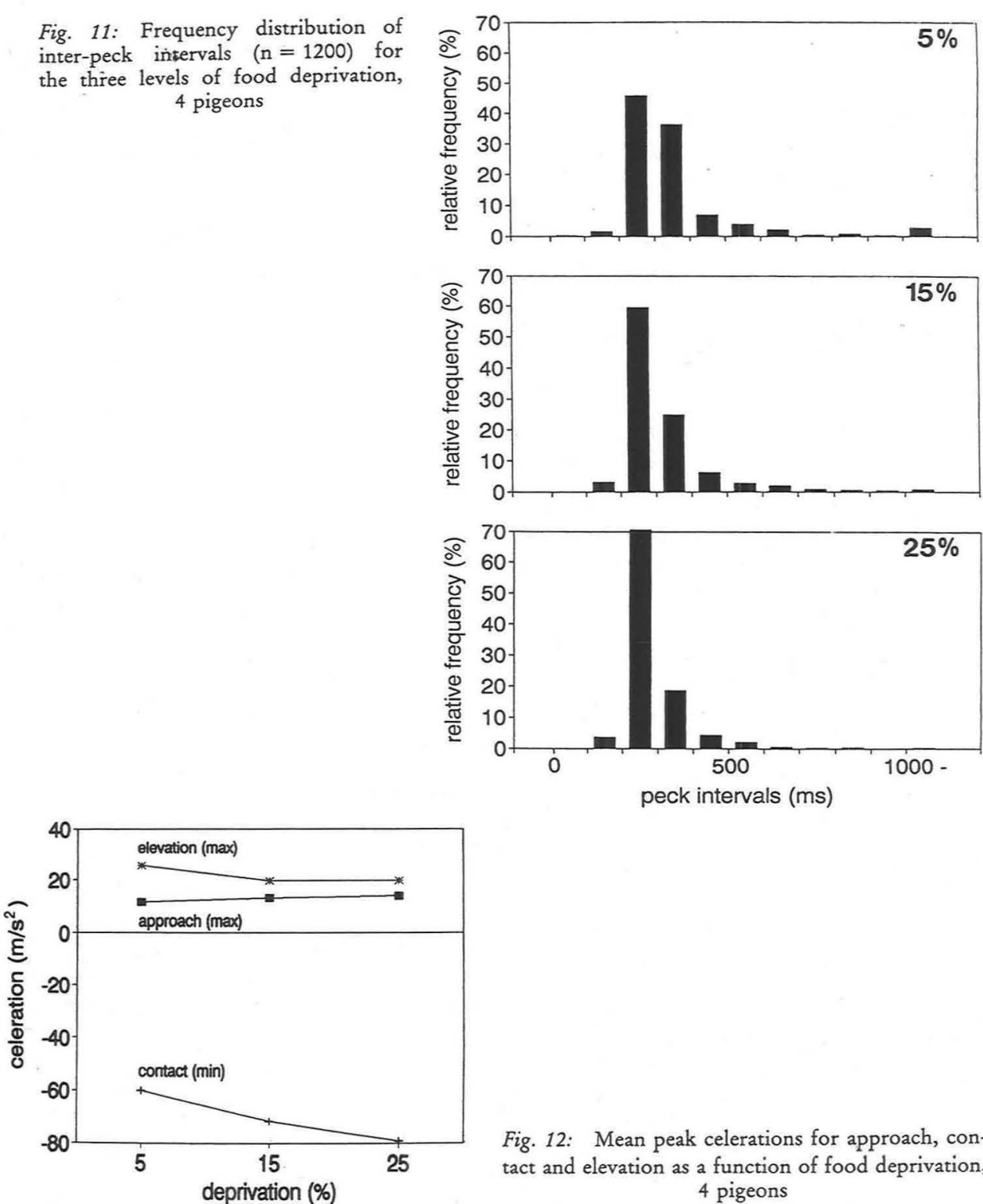

Fig. 12. Mean peak celerations for approach, contact and elevation as a function of food deprivation 4 pigeons

\section{Experiment IV: Effect of Head Loads}

The varying weight of food items ( $a$ few $\mathrm{mg}$ to several $\mathrm{g}$ ) taken up by pigeons involves coping with loads. A check for head load effects was necessary since the accelerometer itself meant some head weighting. Moreover, loads on the primate/ 


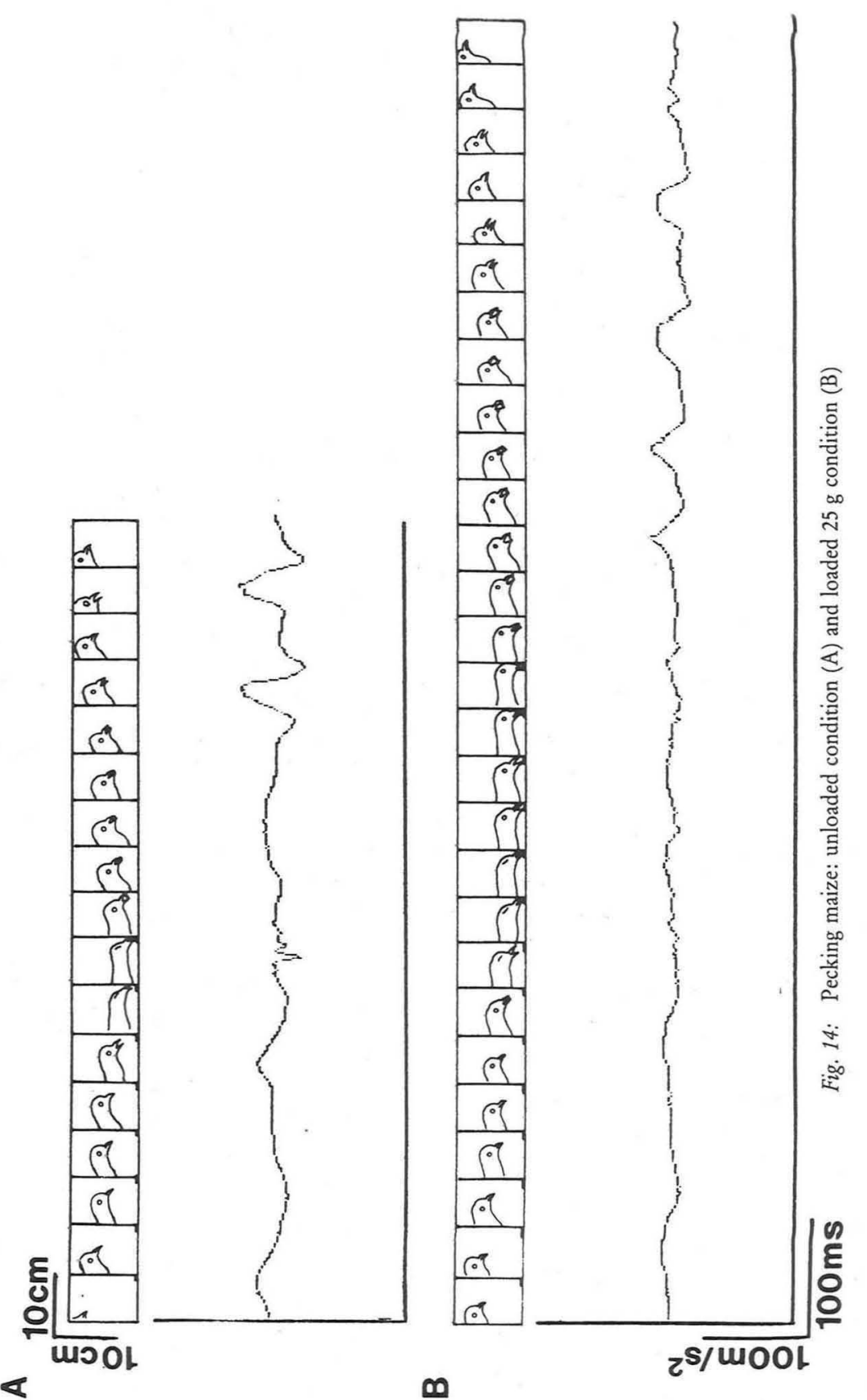

human arm affect grasping movements in revealing ways (DAY \& MARSDEN 1982; Desmedt \& Godaux 1978; Ruitenbeck 1984). Primate head movements are similarly influenced by loads (BIZZI et al. 1978; GAUTHIER et al. 1986).

\section{Methods}

Six pigeons served as subjects. They were deprived to $80 \%$ of free-feeding weight and divided into two groups of 3 . One group participated in an acute load (pigeons \# 1, 2 and 5), the other in a chronic load variant of the experiment (pigeons \# 3,6 and 7). The apparatus was the , the other in a One of two lead weights $(12.5 \mathrm{~g}$ and $25 \mathrm{~g}$, head to load weight ratios approximaly $2: 1$ a $1: 1$ ) were attached to the head blocks (Fig. 13). Iare grains (mize, dipproximately $2: 1$ and $1: 1$ ) transported with throw-and-catch movements, served as food. A sing trial.

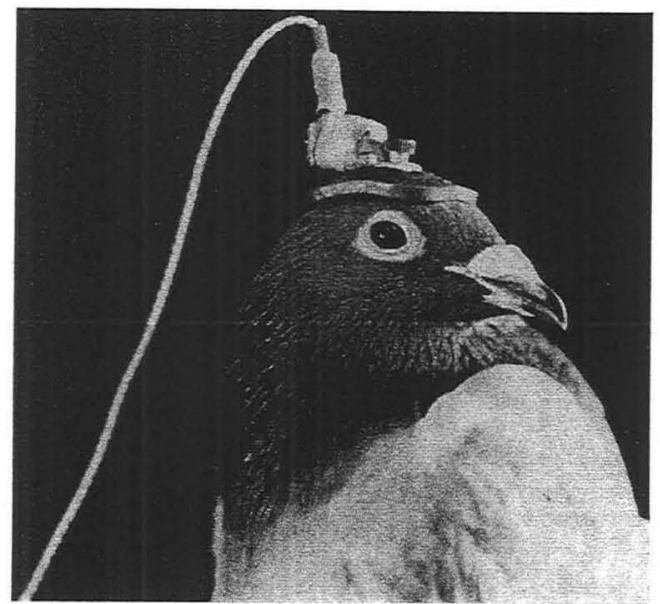

Fig. 13: Pigeon with head-load and accelerometer

The acute condition subjects were equipped with one of the loads and the accelerometer or with the latter alone immediately before a session. The order of treatments was determined by a $3 \times 3$ latin square. The sessions, one per treatment, each consisting of 20 trials and lasting about 20 min, were conducted every second day.

The chronic condition subjects were tested in sessions before loading (pre) and then wore the lighter $(12.5 \mathrm{~g})$ head weight continuously for $18 \mathrm{~d}$ with test sessions taking place immediately after loading $(0 \mathrm{~d})$ and after 9 and $18 \mathrm{~d}$.

\section{Results}

Immediately after head-weighting the pigeons experienced obvious difficulties with pecking. They were, however, soon able to eat. Celerations under load were reduced. This particularly affected the transport head jerks (Fig. 14) that were frequently repeated. But the longer duration of pecks sometimes also resulted from extended grasping efforts (Fig. 14B).

The peak-to-peak celerations of the throw-and-catch movements decreased as a function of the increasing weights under the acute condition (Page test: $\mathrm{L}=42, \mathrm{p}=0.01$; Fig. $15 \mathrm{~A}$ ). Durations of elevation (contact deceleration 
minimum to maximum acceleration final head jerk) were correspondingly longer (Page test: $\mathrm{L}=42, \mathrm{p}=0.01$; Fig. $15 \mathrm{~B}$ ). The duration of the approach phase prior to contact was not affected.

The chronic loading yielded an initial decrease in throw-and-catch celerations but there was some recovery after $9 \mathrm{~d}$ (Page test for pre $>18>9>0$ hypothesis: $\mathrm{L}=88, \mathrm{p}<0.01$; Fig. $15 \mathrm{C}$ ). The elevation phase durations may have been longer initially and adapted somewhat later. Approach durations were again not affected by chronic loading (Fig. 15D).

We also note that the transport phase of ordinary pecks varied across the null conditions of Exp. I to IV. Its duration increased from about 100 to $150 \mathrm{~ms}$ with the smallest grains (millet) over about 130 to $200 \mathrm{~ms}$ for milo and about 300 to $400 \mathrm{~ms}$ for peas to 350 to $450 \mathrm{~ms}$ or more for the largest grains, maize. As remarked before, larger grains elicit more handling movements. The approach phase duration on the contrary, does not seem to vary systematically with grain size.

\section{Discussion}

The head loads had the general effect of increasing movement durations as a result of repeated throw-and-catch movements. Coping strategies minimizing the disturbance developed. One pigeon (\# 6) lifted the head until the beak was in horizontal position before initiating repositioning and transport movements. Another pigeon (\# 7) repositioned the grains with lateral movements similar to those used in head-shaking. These two pigeons did not actually acquire new movement patterns but rather emphasized components that were occasionally
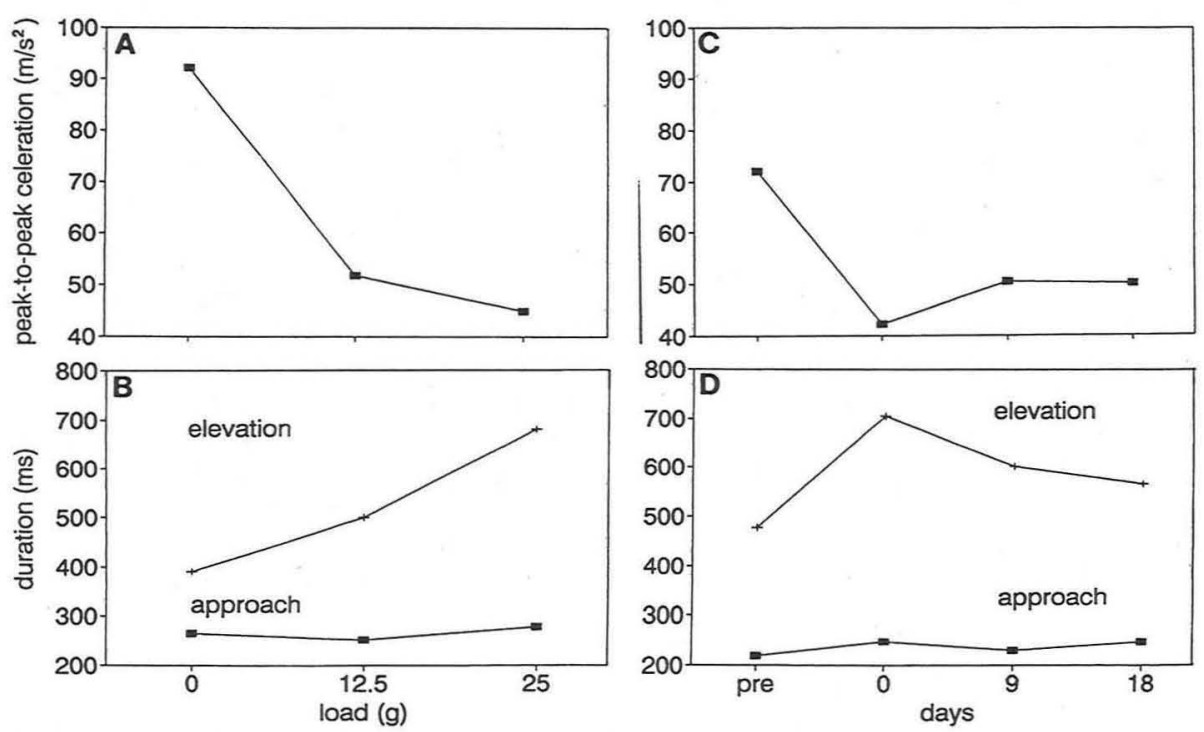

Fig. 15: Acute loading: Mean peak-to-peak transport celerations (A) and approach and elevatio phase durations as a function of acute head loading (B). Same variables as a function of chronic head loading $(\mathrm{C}, \mathrm{D})$. Pre: measurements before loading shown under unloaded conditions. Pigeons \# 1, 2, 3 and 5 only recurred to repeated head jerks. Regardless of this, all pigeons were able to grasp, lift and swallow most grains within the first few trials. Some longer term celeration and duration adjustments occurred in the chronic condition, but they were not particularly salient. According to elementary celeration physics $(c=f / m)$, the pigeons must have almost reflexively increased their muscular force output.

Since heavier loads had limited effect on pecking one can assume that the accelerometer alone (about $4 \mathrm{~g}$ ) had a negligible effect. Measurements with it are thus descriptive of normal head motions.

\section{General Discussion}

The results extend previous descriptions of the pecking of pigeons and document that it is influenced in a variety of ways by several external and internal factors. Whereas previous studies have largely concentrated on studying the pecking of pigeons in undemanding situations we have complicated the foraging contexts and revealed a remarkable adaptability. Pigeons have available or develop peck variants allowing them to uncover food from among non-food items, to forcefully detach it from substrate, to feed when the head's inertia is drastically increased and to augment their pecking efficiency as they are made hungrier. But even in a quite invariant situation (glued grains), peck patterns could differ in several details, both inter- and intraindividually. Pecking is not highly stereotyped but a rather variable response pattern. That is not unexpected from an ecological point of view. Urban pigeons forage on a variety of foods in variety of contexts that call for differing strategies (D. HAAG, pers. comm.). They accordingly seem able to produce well adapted responses in different situations without much trial and error by drawing from a fund of already established coordinations, whether innate or learned.

Pecking may compare in flexibility with human grasping which is dependent on a special anatomical adaptation of the primate hand, the opposition of the thumb (NAPIER 1956). The abduction of the mandibles (BERMEJO \& ZEIGLER 1989) and fingers (PAULIGNAN et al. 1990) initiated shortly before making contact with a target increases proportionally to the target's size. During actual grasping the upper and lower mandibles operate with a precision comparable to the thumb and index finger of the human hand (BEECHER 1951). Position-time and velocity-time profiles are comparable (DEICH et al. 1985). As in human grasping, the control of pecking involves the integration of visual, tactile and proprioceptive information (but see SCHALl \& Delius 1991).

Accelerometry has seldom been used in animal research (MUNDL \& MALMO 1979; RIEHDE 1986; SCHALl 1989). It has proved to be a convenient and informative method for the study of avian pecking. It offers itself for the study of further variables, such as the location of food along the vertical dimension (pigeons are known to harvest seeds off standing plants), the divisibility of food (they often deal with large chunks they can lift but not swallow), the consistency of items (they have obvious difficulties with sticky morsels), the texture of items (they 
sometimes feed on prickly seeds) and not least the taste and odour of food (little is known about the influence of these stimuli upon pecking). As mentioned before, peck-like responses also occur in non-foraging contexts and these may well reveal a further flexibility. More comprehensive descriptions of the pecking act could be achieved by coupling accelerography with goniography (gape opening; BERMEJO et al. 1989), occulography (eye movements; WOHLSCHLÄGER et al., subm.) and myography (muscle activity; ZEIGLER et al. 1992; JÄGER 1991).

Celeration signals are amenable to on-line analysis and offer themselves as a source of controlling feedback in motor learning experiments. Arbitrary criteria such as transverse or low celerations might be set as criteria for food acquisition in an effort to demonstrate that pecking is subject to modification through learning. The technique is also bound to prove a useful supplement in investigations on the sensory and neural mechanisms with recording, ablations and stimulation methods.

\section{Acknowledgements}

The research was supported by grants from the Deutsche Forschungsgemeinschaft. We are grateful to A. NIEMUTH and J. DeLrUs for help with the manuscript and thank Drs. M. ABS, R. JÄGER and W. HÖRSTER for many useful comments and suggestions.

\section{Literature Cited}

ANDREW, R. J. 1983: Lateralization of emotional and cognitive function in higher vertebrates with special reference to the domestic chick. In: Advances in Vertebrate Neuroethology. (EWERT, J. P., Capranica, R. \& Ingle, D. J., eds.) Acad. Press, New York, pp. 477-510.

BARLOW, G. W. 1977: Modal action pattern. In: How Animals communicate. (SEBEOK, T. A., ed.) Univ. Press, Indiana, pp. 98-134.

BEECHER, W. J. 1951: Adaptations for food getting in the American blackbirds. Auk 68, 411-440. Bermejo, R., Allen, R. W., Deich, J. D., Houben, D. \& Zeigler, H. P. 1989: Prehension in the pigeon, I. descriptive analysis. Exp. Brain Res. 75, 569-576.

- $-\&$ ZeIGLER, H.-P. 1989: Trigeminal deafferentation and prehension in the pigeon. Behav. Brain Res. 35, 55-61.

Bizzi, E., Dev, P., Morasso, P. \& Polit, A. 1978: Effect of load disturbances during centrally initiated movements. J. Neurophysiol. 41, 542-556.

BLOCH, S., JÄGER, R., LEMEIGAN, M. \& MARTINOYA, C. 1988: Correlations between ocular saccades and head movement in walking pigeons. J. Physiol. 406, 173.

- - RIVEAUd, S. \& MARTINOYA, C. 1984: Comparing frontal and lateral viewing in the pigeon. III. Different patterns of eye movements for binocular and monocular fixation. Behav. Brain Res. 13, 173-182.

BOND, A. B. 1983: Visual search and selection of natural stimuli in the pigeons: The attention threshold hypothesis. J. Exp. Psych. 9, 292-306.

BORTZ, J., LIENERT, G. A. \& BOEHNKE, K. 1990: Verteilungsfreie Methoden in der Biostatistik. Springer Verl., Berlin.

BROWN, R. G. B. 1969: Seed selection of pigeons. Behaviour 34, 115-131.

DAWKINS, M. 1971: Perceptual changes in chicks: another look at the "search image" concept. Anim. Behav. 19, 566-574.

DAY, B. L. \& MARSDEN, C. D. 1982: Accurate repositioning of the human thumb against unpredictable dynamic loads is dependent upon peripherical feedback. J. Physiol. (London) 327, 393-407.

Deich, J. R., Klein, B. G. \& Zeigler, H. P. 1985: Grasping in the pigeon: Motor control mechanisms. Brain Res. 337, 362-367.
DeLIUS, J. D. 1983: Learning. In: Physiology and Behaviour of the Pigeon. (ABS, M., ed.) Acad. ress, London, pp. 327-355.

- 1985: The peck of the pigeon - free for all. In: Behavior Analysis and Contemporary Psychology. (Lowe, C. F., Richelle, M., Blackman, D. E. \& Bradshaw, C. M., eds.) Erlbaum, Hillsdale, pp. 53-81.

- 1988: Preening and associated comfort behaviour in birds. Ann. New York Acad. Sci. 525, $40-55$.

DESMEDT, J. E. \& GODAUX, E. 1978: Ballistic skilled movements: Load compensation \& patterning of the motor commands. Prog. Clin. Neurophysiol. 4, 21-55.

Emmerton, J. 1983: Vision. In: Physiology and Behavior of the Pigeon. (ABS, M., ed.) Acad. Press, New York, pp. 245-266.

FABRICIUS, E. \& JANSSON, A. M. 1963: Laboratory observations on the reproductive behaviour of the pigeon (Columba livia) during the preincubation phase of the breeding cycle. Anim. Behav. pigeon (Colum

FrIEDMAN, M. B. 1975: How birds use their eyes. In: Neural and Endocrine Aspects of Behaviour in Birds. (Wright, P., CARYL, P. G. \& Vowles, D. M., eds.) Elsevier, Amsterdam, pp. $181-204$.

GAITPR, G. M. MARTIN, B. J. \& STARK, L. W. 1986: Adapted head \& eye movement responses to added head inertia. Aviat. Space Environ. Med. 57, 336-342.

GEIIERMANN, L. W. 1933: Chance orders of alternating stimuli in visual discrimination experiments. J. Genet. Psych. 42, 206-208.

GOODALE, M. A. 1983: Visually guided pecking in the pigeon (Columba livia). Brain Behav. Evol. $22,22-41$.

GÜNTÜRKÜN, O. \& KESCH, S. 1987: Visual lateralization during feeding in pigeons. Behav. Neurosci. 101, $433-435$.

HAAG, D. 1991: Ethogramm der Taube. Abs and Galhoff, Bochum.
JÄGER, R. 1990: Visuomotor feeding perturbations after lateral telencephalic lesions in pigeons.

Behav. Brain Res. $40,73-80$.
-1991 : Neck muscle activity during pecking in the pigeon. In: Synapse, Transmission, Modulation. (ELSNER, N. \& PENZLIN, H., eds.) Thieme, Stuttgart, pp. 58

JAHNKE, H. J. 1984: Binocular field differences among various breeds of pigeons. Bird Behav. 5 , 96-102.

LAMON, B. \& ZEIGLER, H. P. 1984: Grasping in the pigeon: Stimulus control during conditioned and consummatory responses. Anim. Learn. Behav. 12, 223-231.

LINDENBLATT, U. \& DeLIUS, J. D. 1987: Apomorphine-induced pecking in pigeons classically conditioned to environmental cues. Psychopharmacol. 93, 223-225.

Mallin, H. D. \& Delius, J. D. 1983: Inter- and intraocular transfer of colour discriminations with mandibulation as an operant in the head-fixed pigeon. Behav. Anal. Lett. 3, 297-309.

Martinoya, C., Le Houezec, J. \& Bloch, S. 1984: Pigeon's eyes converge during feeding: evidence for frontal binocular fixation in a lateral-eyed bird. Neurosci. Lett. 45, 335-339.

Megibow, M. \& Zeigler, H. P. 1968: Readiness to eat in the pigeon. Psychon. Sci. 12, 17-18.

MOON, R. D. \& ZEIGLER, H. P. 1979: Food preferences in the pigeons (Columba livia). Physiol. Behav. 22, 1171-1182.

MUNDL, W. J. \& MALMO, H. P. 1979: An accelerometer for recording head movement of laboratory animals. Physiol. Behav. 23, 391-393.

NAPIER, J. R. 1956: The prehensile movement of the human hand. J. Bone Joint Surg. 38 B, 902-913. NAPIER, J. R. 1956: The prehensile movement
NIGG, B. 1977: Biomechanik. Juris, Zürich.

NIGG, B. 1977: Biomechanik. Juris, Zürich. finger movements during prehension. Exp. Brain Res. 79, 431-435.

PeLLIS, S. M. 1985: What is "fixed" in a fixed action pattern? A problem of methodology. Bird Behav. 6, 10-15.

Penzlin, H. 1980: Lehrbuch der Tierphysiologie. Fischer, Stuttgart.

RAMIREZ, J. M. \& DELIUS, J. D. 1978: Aggressive behaviour of pigeons: suppression by archistriatal lesions. Aggress. Behav. 5, 3-17.

RIEHDE, D. 1986: Dreidimensionale Bewegung des Pferderückens. In: Therapeutisches Reiten in der Krankengymnastik. (RIEHDE, D., ed.) Pflaum, München. 
RUITENBECK, J. C. 1984: Invariants in loaded goal directed movements. Biol. Cyber. 51, 11-20. SCHALL, U. 1989: Sensory Control of Pecking in the Pigeon (Columba livia). Centaurus, Pfaffenweiler.

\& DELIUS, J. D. 1991: Grasping in the pigeon: control through sound and vibration feedhack mediated by the nucleus basalis. Physiol. Behav. 50, $983-988$.

SCHLEIDT; W. M. 1974: How "fixed" is fixed action pattern? Z. Tierpsychol. 36, 184-211.

THORPE, W. H. 1951: The definition of terms used in animal behaviour studies. Bull. Anim. Behav. 9, $34-40$

Tinbergen, N. 1951: The Study of Instinct. Oxford Univ. Press, Oxford.

WEISS, D. E. 1947: Design and application of accelerometers. Proc. Soc. Exp. Stress Anal. 4, 89-99.

ZeIGLeR, H. P., LewITT, P. W. \& LeVINE, R. R. 1980: Eating in the pigeon. Movement patterns, stereotypy and stimulus control. J. Comp. Physiol. Psych. 74, 783-794.

- Miller, M. \& LEVINE, R. R. 1975. Trigeminal nerve \& eating in the pigeon (Columba livia): Neurosensory control of the consummatory responses. J. Comp. Physiol. Psychol. 89, $845-858$.

ZWEERS, G. A. 1982 a: Pecking of the pigeon (Columba livia L.). Behaviour 81, 173-230.
--1982 b: Drinking of the pigeon (Columba livia L.). Behaviour 80, 274-317. 